\title{
PENGARUH PEMBELAJARAN MIND MAPPING TERHADAP HASIL BELAJAR SISWA PADA MATERI MEMAHAMI DASAR-DASAR ELEKTRONIKA SEDERHANA
}

\author{
Adi Hardian ${ }^{1}$, Debora ${ }^{2}$, Wiyogo ${ }^{3}$ \\ ${ }^{1,2,3}$ Fakultas Keguruan dan Ilmu Pendidikan Universitas Palangka Raya \\ E-mail: adhie4dikunge@gmail.com
}

\begin{abstract}
The purpose of this study is knowing the mind maping learning strategies against student learning outcomes in understanding simple electronic basics lesson. This research is a type of pre-experimental research with the method of a pretest-posttest design group. Samples from this study were students of class $\mathrm{X}$ in motorcycle engineering (TBSM) who numbered 19 people. Research data is quantitative data from learning outcomes test instruments in the form of pretest scores and posttest scores. Instrument test results from 50 multiple choice choices items obtained 30 questions received to be used as instruments in this research. Parametric hypothesis test results obtained price calculate $>t$ table $(6,21>2,03)$. Because $t=6,21$ is greater than $\mathrm{t}$ table $=2,03$, so this means $\mathrm{H}_{1}$ is received, what is required about learning strategies mind mapping of student learning outcomes in lesson material understanding simple electronic basics. Results can be investigated student learning outcomes after learning with learning strategies mind mapping is better than student learning outcome before learning with learning strategies mind mapping.
\end{abstract}

Keywords: Mind Mapping, Simple Electronic, Learning Outcomes.

\section{PENDAHULUAN}

Pendidikan merupakan bagian penting dalam proses pembangunan suatu negara berkembang seperti Indonesia. Undang-Undang Nomor 20 Tahun 2003 tentang Sistem Pendidikan di Indonesia menyatakan bahwa pendidikan merupakan usaha sadar untuk mewujudkan suasana belajar dan proses pembelajaran agar peserta didik secara aktif mengembangkan potensi dirinya untuk memiliki kukuatan spiritual keagamaan, pengendalian diri, kepribadian, kecerdasan, ahlak mulia, serta keterampilan yang diperlukan dirinya, masyarakat, bangsa dan negara. Untuk meningkatkan itu semua maka manusia di tuntut untuk belajar.

Belajar merupakan suatu proses perubahan tingkah laku individu melalui interaksi dengan lingkungan. Menurut Undang-Undang Nomor 20 Tahun 2003 pasal 1 ayat 20, pembelajaran adalah proses interaksi peserta didik dengan pendidik dan sumber belajar pada suatu lingkungan belajar. Artinya belajar adalah hasil dari interaksi seorang dengan sumber-sumber belajar pada suatu lingkungan. Lingkungan belajar tidak hanya sekolah, dapat pula berupa sanggar, tempat ibadah, masyarakat, keluarga, dan lembaga-lembaga pendidikan nonformal. Pada tingkat satuan pendidikan atau sekolah, kelas merupakan lingkungan belajar yang pengelolaannya sepenuhnya menjadi tanggung jawab guru pada saat berlangsungnya proses pembelajaran.

Mulyasa (2011) menyatakan guru dapat diibaratkan sebagai pembimbing perjalanan, yang berdasaarkan pengetahuan dan pengalamannya bertanggung jawab atas kelancaran perjalanan itu, tidak hanya secara fisik tetapi juga perjalanan mental, emosional, kreativitas, moral, dan spiritual yang lebih dalam dan kompleks. Dalam hal ini perencanaan pembelajaran guru menekankan pada keaktifan siswa, suasana kondusif, pembelajaran yang efektif dan suasana yang menyenangkan menjadi prioritas utama dalam proses pembelajaran. Interaksi antara guru dan siswa akan mempermudah siswa menerima dan mempelajari pelajaran. Guru dan buku teks merupakan sumber belajar bagi siswa selama di sekolah. Namun sumber belajar bukan hanya sebatas guru dan buku teks karena mengingat pengertian sumber belajar adalah semua sumber (baik berupa data atau benda) yang dapat digunakan untuk memberi fasilitas (kemudahan) belajar bagi siswa. Sumber belajar ini bermanfaat dalam memberikan sumbangan yang positif untuk peningkatan mutu pendidikan dan pembelajaran. Jadi sumber belajar yang lain bisa diperoleh siswa dengan terjun langsung di luar sekolah. Siswa bisa belajar dari lingkungan sekitar wilayah mereka belajar karena di sekolah merupakan sumber belajar bagi siswa maka guru harus mengetahui dan menguasai berbagai model, metode, strategi, serta media pembelajaran agar peserta didik lebih aktif dalam pembelajaran di kelas. 
Berdasarkan observasi dan wawancara dengan siswa kelas X Teknik Bisnis Sepeda Motor (TBSM) SMK Negeri 8 Palangka Raya, guru menggunakan model pembelajaran konvesional pada materi pelajaran memahami dasar-dasar elektronika sederhana. Hasil belajar siswa pada mata pelajaran memahami dasar-dasar elektronika sederhana kelas X TBSM SMK Negeri 8 Palangka Raya tahun ajaran 2018/2019, masih tergolong rendah karena siswa kurang memperhatikan materi yang disampaikan oleh guru. Kendala selama proses belajar mengajar di kelas di antaranya adalah siswa kurang fokus mengikuti pembelajaran, siswa kurang memperhatikan guru, minat belajar siswa di kelas rendah, lebih banyak yang pasif dan perhatiannya mudah teralihkan saat pembelajaran berlangsung.

Guru membutuhkan strategi pembelajaran yang tepat dan efektif untuk mengoptimalkan pemahaman siswa pada materi pelajaran dasar-dasar elektronika sederhana. Salah satu alternatifnya adalah dengan menggunakan strategi mind mapping. Mind mapping adalah suatu teknik grafis yang memungkinkan kita untuk mengeksplorasi seluruh kemampuan otak kita untuk keperluan berpikir dan belajar.

Alasan penggunaan strategi pembelajaran mind mapping pada materi memahami dasar-dasar elektronika sederhana karena siswa diharuskan menguasai pemahaman mengenai dasar-dasar elektronika, komponen-komponen serta fungsi dari komponen. Dalam proses pembelajaran bukan hanya sekedar transfer pengetahuan dari guru ke siswa, seperti dalam falsafah behaviorisme, tetapi merupakan proses pemerolehan konsep yang berorientasi pada keterlibatan siswa secara aktif dan langsung. Dengan penggunaan strategi pembelajaran mind mapping, proses pembelajaran akan lebih bermakna dimana strategi pembelajaran mind mapping juga dapat meningkatkan daya ingat siswa terhadap materi pada saat pembelajaran.

Berdasarkan latar belakang masalah yang telah diuraikan, terdapat beberapa masalah yang muncul dalam kegiatan belajar mengajar yang dapat diidentifikasi sebagai berikut: (1) guru masih menggunakan model pembelajaran konvensional pada saat mengajar, sehingga membuat siswa kurang aktif pada saat pembelajaran; (2) kurangnya penggunaan variasi pada saat pembelajaran di kelas; (3) perlu adanya penggunaan strategi pembelajaran yang mendorong keterlibatan siswa dalam proses belajar mengajar dan memotivasi siswa untuk dapat lebih memahami materi pembelajaran; dan (4) hasil belajar yang diukur hanya pada ranah kognitif.

\section{METODE}

Metode penelitian yang digunakan dalam penelitian ini adalah metode pre-experimental design atau merupakan eksperimen yang tidak sebenarnya. Metode ini sering disebut juga dengan istilah quasi experiment. Disebut demikian karena masih terdapat variabel luar yang ikut berpengaruh terhadap terbentuknya variabel dependen (variabel terikat). Hasil eksperimen yang merupakan variabel terikat bukan semata-mata dipengaruhi oleh variabel bebas. Hal itu dapat terjadi karena tidak adanya variabel kontrol, dan sampel tidak dipilih secara random (Sugiyono, 2011).

Desain penelitian menggunakan one-group pretest-posttest design, yaitu hanya terdapat satu kelompok yang digunakan untuk penelitian, tidak ada kelompok kontrol. Observasi dilakukan dua kali, yaitu sebelum dan sesudah eksperimen. Observasi yang dilakukan sebelum eksperimen $\left(\mathrm{O}_{1}\right)$ disebut pretest, dan observasi sesudah eksperimen $\left(\mathrm{O}_{2}\right)$ disebut posttest. Perbedaan antara $\mathrm{O}_{1}$ dan $\mathrm{O}_{2}$ yakni $\mathrm{O}_{1}-\mathrm{O}_{2}$ diasumsikan merupakan efek dari treatment atau eksperimen. Dengan demikian hasil perlakuan dapat diketahui lebih akurat dengan sebelum diberi perlakuan.

Populasi dalam penelitian ini adalah seluruh siswa kelas X TBSM SMK Negeri 8 Palangka Raya, yang terdaftar pada semester genap tahun ajaran 2018/2019 berjumlah 19 siswa. Sampel dalam penelitian ini adalah seluruh populasi yang diambil menggunakan teknik purposive sampling. Teknik purposive sampling adalah teknik menentukan sampel dengan pertimbangan tertentu (Sugiyono, 2011). Yang menjadi sampel penelitian ini adalah kelas X TBSM SMK Negeri 8 Palangka Raya. Secara umum penelitian ini dibagi dalam tiga tahap, yaitu persiapan dan perencanaan, pelaksanaan dan pelaporan. 


\section{HASIL DAN DISKUSI}

Instrumen penelitian berupa tes tertulis berbentuk pilihan ganda sebanyak 50 butir soal dengan 4 opsi pilihan jawaban, diujicoba pada kelas X TBSM SMK Negeri 1 Palangka Raya dengan jumlah siswa sebanyak 30 orang. Uji coba instrumen dilakukan dengan tujuan untuk mengetahui koefisien validitas, reabilitas, daya pembeda dan indek kesekuran. Setelah dilakukan ujicoba, didapat 31 butir soal valid dengan angka koefisien reabilitas sebesar 0,91. Berdasarkan hasil pengujian validitas, reabilitas, daya pembeda, dan indek kesukaran, hanya 31 soal yang dijadikan sebagai instrument tes hasil belajar dalam penelitian ini.

\section{Hasil}

Hasil olah data penelitian disajikan dalam Tabel 1. Berdasarkan Tabel 1 diketahui bahwa ratarata nilai pretest siswa kelas X TBSM sebelum dibelajarkan dengan strategi pembelajaran mind mapping adalah sebesar 58,59, dimana dari 19 siswa terdapat 3 siswa yang dinyatakan tuntas dan 16 siswa yang nilainya di bawah KKM dengan presentase $15,78 \%$ dengan perolehan nilai tertinggi adalah 70 dan nilai terendah 50. Hasil belajar siswa pada materi pelajaran memahami dasar-dasar elektronika sederhana kembali diukur melalui tes hasil belajar setelah perlakuan menggunakan strategi pembelajaran mind mapping. Hasilnya diketahui bahwa rata-rata nilai akhir siswa kelas $\mathrm{X}$ TBSM setelah treatment dengan strategi pembelajaran mind mapping adalah 71,74. Dimana dari 19 orang siswa terdapat 14 siswa dinyatakan tuntas dan 5 siswa yang nilainya dibawah nilai KKM (tidak tuntas), adapun presentase ketuntasan belajar siswa pada materi pelajaran memahami dasar-dasar elektronika sederhana di kelas X TBSM adalah 73,68 \%. Dengan nilai terendah 57 dan nilai tertinggi 80. Dari Tabel 1 juga menunjukkan peningkatan efektifitas siswa berdasarkan gain individu, sedangkan skor gain rata-rata adalah 0,31 dengan kata lain, peningkatan kompetensi individu siswa rata-rata dalam kategori sedang.

Tabel 1. Data Hasil Tes Awal (Pretest), Tes Akhir (Posttest), dan Analisa N-Gain

\begin{tabular}{|c|l|c|c|c|c|c|c|}
\hline NO & \multicolumn{1}{|c|}{ NAMA SISW A } & JB & Pretest & JB & Posttest & Presentase & $\begin{array}{c}\text { Interpretasi } \\
\text { N-Gain }\end{array}$ \\
\hline $\mathbf{1}$ & Agung yanuar & 16 & 53 & 22 & 73 & 0.43 & Sedang \\
\hline $\mathbf{2}$ & Ahmad alpian & 20 & 67 & 22 & 73 & 0.20 & Rendah \\
\hline $\mathbf{3}$ & Ahmad habibi & 16 & 53 & 24 & 80 & 0.57 & Sedang \\
\hline $\mathbf{4}$ & Ahmad soleh nuraripin & 16 & 53 & 22 & 73 & 0.43 & Sedang \\
\hline $\mathbf{5}$ & Andika saputra & 15 & 50 & 19 & 63 & 0.27 & Rendah \\
\hline $\mathbf{6}$ & Aris setrya wibowo & 17 & 57 & 19 & 63 & 0.15 & Rendah \\
\hline $\mathbf{7}$ & Aryansyah & 18 & 60 & 20 & 67 & 0.17 & Rendah \\
\hline $\mathbf{8}$ & Boy hanimas & 16 & 53 & 22 & 73 & 0.43 & Sedang \\
\hline $\mathbf{9}$ & Devito kumiawan & 21 & 70 & 24 & 80 & 0.33 & Sedang \\
\hline $\mathbf{1 0}$ & Dian pratama putra & 16 & 53 & 21 & 70 & 0.36 & Sedang \\
\hline $\mathbf{1 1}$ & Eko arifianto putra suri & 17 & 57 & 20 & 67 & 0.23 & Rendah \\
\hline $\mathbf{1 2}$ & Ferdian axcel haryono & 17 & 57 & 22 & 73 & 0.38 & Sedang \\
\hline $\mathbf{1 3}$ & Johan yoga prasetio & 19 & 63 & 21 & 70 & 0.18 & Rendah \\
\hline $\mathbf{1 4}$ & Maryo ariski & 15 & 50 & 17 & 57 & 0.13 & Rendah \\
\hline $\mathbf{1 5}$ & Moch ryan ashabul kha & 20 & 67 & 24 & 80 & 0.40 & Sedang \\
\hline $\mathbf{1 6}$ & Muhamad noor qosim & 21 & 70 & 24 & 80 & 0.33 & Sedang \\
\hline $\mathbf{1 7}$ & Muhamad renaldi & 17 & 57 & 21 & 70 & 0.31 & Sedang \\
\hline $\mathbf{1 8}$ & Muhamad dony & 16 & 53 & 22 & 73 & 0.43 & Sedang \\
\hline $\mathbf{1 9}$ & Riyan rahmanto & 21 & 70 & 23 & 77 & 0.22 & Rendah \\
\hline & jumlah & 334 & 1113.333 & 409 & 1363.2 & 5.95372672 & Tinggi \\
\hline & rata-rata & 17.579 & 58.59649 & 21.53 & 71.7472 & 0.31335404 & Sedang \\
\hline
\end{tabular}

Pada taraf signifikansi $(\alpha)=5 \%$ dan $\mathrm{dk}=\mathrm{n}_{1}+\mathrm{n}_{2}-2=36$ diperoleh harga $\mathrm{t}_{\text {tabel }}=2,03$. Dari perhitungan diatas diperoleh $t_{\text {hitung }}=6,21$. Maka hasilnya sebagai berikut: $t_{\text {hitung }}$ lebih besar dari $t_{\text {tabel }}$ $(6,21>2,03)$. Hal ini berarti $\mathrm{H}_{1}$ diterima dan $\mathrm{H}_{0}$ ditolak, dan kesimpulannya adalah terdapat pengaruh pada hasil belajar siswa yang diajarkan dengan menggunakan strategi pembelajaran mind mapping 
pada materi pelajaran dasar-dasar elektronika sederhana di kelas X TBSM SMK Negeri 8 Palangka Raya Tahun Ajaran 2018/2019. Hasil uji hipotesis disajikan dalam Tabel 2.

Tabel 2. Besaran Untuk Menguji Hipotesis

\begin{tabular}{lll}
\hline Kelompok & Pretest $\left({ }_{1}\right)$ & Posttest $(2)$ \\
\hline Rata-rata $(X)$ & 58,59 & 71,75 \\
Standar Deviasi (SD) & 6,77 & 6,25 \\
Varian $\left(\mathrm{S}^{2}\right)$ & 45,89 & 39,02 \\
$\mathrm{n}$ & 19 & 19 \\
\hline $\mathrm{T}_{\text {hitung }}$ & 6,21 & \\
\hline $\mathrm{T}_{\text {tabel }}$ & 2,03 & \\
\hline
\end{tabular}

\section{Diskusi}

Berdasarkan analisis data penelitian, diperoleh hasil bahwa terdapat perbedaan rata-rata hasil pretest dengan posttest dengan selisih yang cukup besar. Dimana kemampuan awal siswa dapat dilihat dari nilai rata-rata pretest yaitu 58,54. Setelah dilakukan pembelajaran dengan strategi pembelajaran Mind mapping rata-rata hasil belajar siswa adalah 71,75. Berdasarkan uji $\mathrm{N}$-gain didapatkan skor gain rata-rata siswa adalah 0,32 atau peningkatan kompetensi individu siswa rata-rata dalam kategori sedang. Dari hasil uji normalitas dan uji homogenitas diperoleh hasil bahwa data pretest dan posttest berdistribusi normal dan homogen, sehingga pada uji hipotesis digunakan uji-t dua pihak dengan sampel berkorelasi. Berdasarkan uji statistik parametris yang dilakukan menghasilkan $t_{\text {hitung }}>t_{\text {tabel }}$ $(6,21>2,03)$. Dengan demikian dapat disimpulkan bahwa "Terdapat pengaruh terhadap hasil belajar Siswa yang signifikan setelah dibelajarkan dengan Strategi pembelajaran Mind mapping pada kopetensi dasar memahami dasar-dasar elektronika sederhana di kelas X TBSM SMK Negeri 8 Palangka Raya". Hal ini menunjukkan bahwa hasil belajar siswa yang menggunakan strategi pembelajaran mind mapping lebih baik daripada hasil belajar siswa sebelum menggunakan strategi pembelajaran mind mapping.

Gambar 1 adalah grafik perbandingan hasil belajar siswa sesudah dibelajarkan dengan strategi pembelajaran mind mapping dengan hasil belajar siswa sebelum dibelajarkan dengan strategi pembelajaran mind mapping.

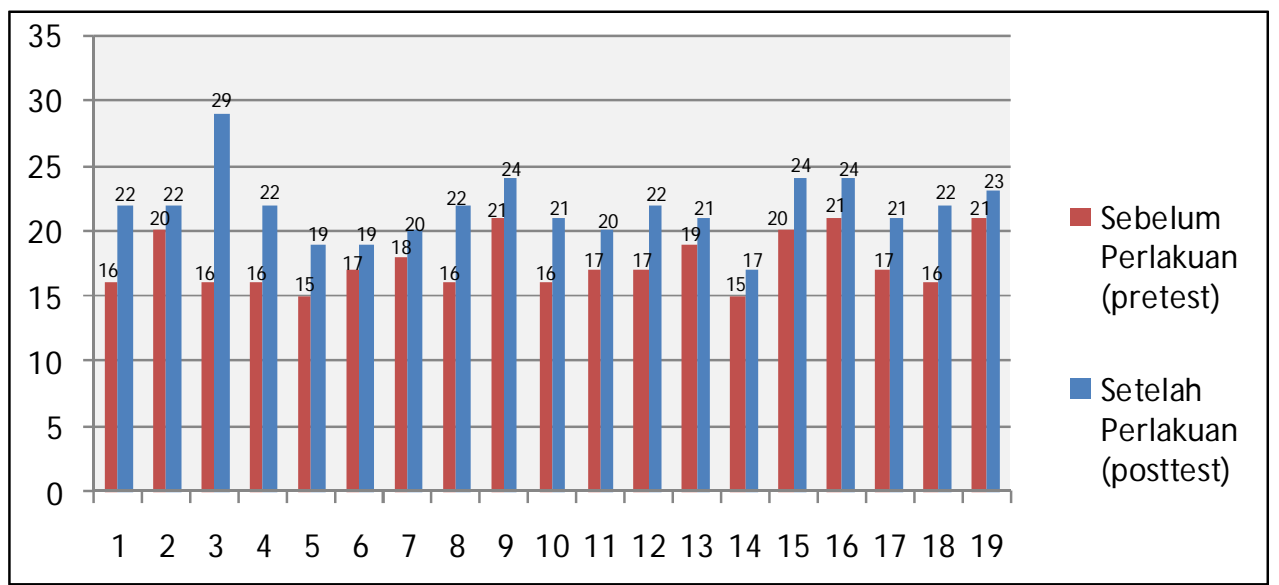

Gambar 1. Grafik Perbandingan Hasil Belajar Siswa Pretest dan Posttets

Dari Gambar 1, dapat kita lihat bahwa terjadi peningkatan hasil belajar siswa antara sebelum dengn sesudah dibelajarkan dengan strategi pembelajaran mind mapping, secara individu peningkatan yang terjadi cukup bervariasi dan dalam kategori sedang. Secara keseluruhan, meskipun hasil belajar 
siswa setelah perlakuan (posttest) rata-ratanya hanya 71,75, tetapi hal itu merpakan peningkatan yang cukup baik apabila dibandingkan dengan hasil belajar siswa sebelum diberi perlakuan (pretest), yang rata-ratnya 58,59. Dengan demikian dapat disimpulkan bahwa, hasil belajar siswa setelah dibelajarkan dengan strategi pembelajaran mind mapping lebih baik dibandingkan dengan hasil belajar siswa sebelum dibelajarkan dengan strategi pembelajaran mind mapping.

\section{SIMPULAN}

Berdasarkan hasil analisis data yang telah diuraikan, maka dapat disimpulkan bahwa terdapat pengaruh strategi pembelajaran mind mapping terhadap hasil belajar siswa pada materi pelajaran memahami dasar-dasar elektoronika sederhana.

Berdasarkan hasil penelitian, dituliskan saran sebagai berikut: (1) guru dapat menjadikan strategi pembelajaran mind mapping sebagai alternatif pembelajaran pada materi memahami dasardasar elektronika sederhana; (2) bagi kepala sekolah agar dapat membantu dan mengarahkan guruguru untuk menggunakan cara-cara pemebalajaran yang aktif, kreatif, efektif dan menyenangkan untuk meningkatkan kemampuan peserta didik; (3) untuk menerapkan strategi pembelajaran mind mapping, guru harus mepersiapkan segala sesuatunya secara matang. Sehingga pembelajaran berjalan secara sistematis sesuai dengan rencana dan berlangsung secara efektif; dan (4) siswa hendaknya tidak dipandang sebagai pihak yang menerima pembelajaran, tetapi harus dipandang sebagai pihak yang aktif dan perlu dilibatkan dalam setiap proses pembalajaran. Karena pembelajaran yang berpusat pada siswa tentunya lebih menarik minat siswa.

\section{UCAPAN TERIMA KASIH}

Ucapan terima kasih kepada pembimbing yang telah mengarahkan dalam penyelesaian artikel ini yaitu: (1) Dr. Debora, M.Pd selaku dosen pembimbing I; dan (2) Wiyogo, ST.MT selaku dosen Pembimbing II.

\section{DAFTAR RUJUKAN}

Mulyasa. 2011. Menjadi Guru Profesional. Bandung: PT Remaja Rosdakara

Sugiyono. 2011. Metode Penelitian Pendidikan. Bandung: Alfabeta

Undang-Undang Nomor 20 Tahun 2003 tentang Sistem Pendidikan Nasional. 